\title{
Chitosan/Cellulose Nanofibril Nanocomposite and Its Effect on Quality of Coated Strawberries
}

\author{
N. S. Resende $\mathbb{D}^{\mathbb{D}},{ }^{1}$ G. A. S. Gonçalves, ${ }^{2}$ K. C. Reis, ${ }^{3}$ G. H. D. Tonoli, ${ }^{3}$ and E. V. B. V. Boas $\mathbb{I D}^{1}$ \\ ${ }^{1}$ Food Science Department, Federal University of Lavras, University Campus, Lavras, MG, Brazil \\ ${ }^{2}$ Federal Institute of Education, Science and Technology, Southeast Barbacena Campus, \\ Barbacena, MG, Brazil \\ ${ }^{3}$ Department of Forestry, Federal University of Lavras, University Campus, Lavras, MG, Brazil
}

Correspondence should be addressed to E.V. B.V. Boas; evbvboas@dca.ufla.br

Received 7 July 2017; Revised 6 October 2017; Accepted 12 April 2018; Published 5 July 2018

Academic Editor: Sandra Olimpia Mendoza

Copyright ( $) 2018$ N. S. Resende et al. This is an open access article distributed under the Creative Commons Attribution License, which permits unrestricted use, distribution, and reproduction in any medium, provided the original work is properly cited.

\begin{abstract}
The aim of this study was to develop a chitosan/cellulose nanofibril (CNF) nanocomposite and evaluate its effect on strawberry's postharvest quality after coating. From the results of color, thickness, and scanning electron microscopy (SEM) and permeability to water vapor analyses, the best film formulation for coating strawberries was determined. Three coating formulations were prepared: $1 \%$ chitosan, $1 \%$ chitosan $+3 \% \mathrm{CNF}$, and $1 \%$ chitosan $+5 \% \mathrm{CNF}$. The strawberries were immersed in the filmogenic solutions and kept under cold storage $\left(1 \pm 1^{\circ} \mathrm{C}\right)$. The color of the film was not affected by increased concentration of cellulose nanofibrils; however, the thickness and water vapor permeability were affected by the CNF addition. The coating with the highest CNF concentration performed better in reducing fruit mass and firmness loss. The color was positively influenced by the addition of the coating, regardless of formulation, as well as soluble solid content, PG enzymatic activity, and the fruit appearance. The $\mathrm{pH}$ and titratable acidity showed no significant difference among treatments. It was observed that the vitamin C, phenolic compounds, and anthocyanin content, as well as the PAL activity and the antioxidant activity (except for \% protection), were affected by chitosan coating, however not by the addition of CNFs.
\end{abstract}

\section{Introduction}

Consumption of healthy foods accompanies the increase in life expectancy; thus, healthy habits are increasingly present in everyday life. Food should not only meet the basic nutritional needs, since the actual present demand is for food that acts preventing possible pathologies [1]. In this scenario, red fruits such as strawberry stand out, since besides great sensory acceptance, they have significant concentrations of phenolic compounds, highly associated with chronic disease prevention [2].

The strawberry has a reduced life due to various intrinsic factors: high respiration rate, very thin epidermis, and susceptibility to contamination by microorganisms, among others. Those, combined with extrinsic factors such as faults during transport, handling, and lack of refrigeration, make the loss of this fruit reach $40 \%$ of the total planted. Being a high-value product, particularly in the fresh market, strawberries require appropriate technologies to improve their conservation and extend their market availability.
A viable alternative to increase the postharvest conservation of fruits and vegetables is the application of edible films [3]. In fruit preferably consumed fresh, such as strawberry, application of edible and biodegradable material films becomes a very promising technology [4]. In addition, efforts to reduce the packaging flow and the currently generated waste are closely linked with the increased awareness of the population that values products having renewable materials in their composition, or that eliminates, even partially, polluting materials [5].

A special emphasis has been given to chitosan because of its filmogenic properties and nontoxic nature, allowing its safe use. It is the second most abundant polysaccharide in nature and has the capacity to form films with proven antimicrobial properties [6].

The wide availability, low weight, and cost of natural fibers make them a material with considerable applicability in composites [7, 8]. Fractionation of the fibers and the use of their constituents have been shown to be an important area for research. Within this field, cellulose nanofibril has considerable 
potential for use as reinforcement in polymers, due to its capacity to confer characteristics comparable to those achieved with synthetic materials $[9,10]$.

It is noteworthy that cellulose nanocomposites are one of the most promising structures to the packaging field [11-14].

To enable the strawberry commercialization, especially the fruit in natura, the implementation of new postharvest techniques is required in order to extend the supply.

The objective of this study was to develop chitosan/cellulose nanofiber bionanocomposites, characterize them about their physical, microstructural, and permeability properties, and evaluate their effect on strawberry's postharvest life as a coating layer.

\section{Materials and Methods}

The experiment was conducted in two stages: The first stage was the preparation of chitosan/cellulose nanofiber bionanocomposites, and the second stage was their application as coating of strawberry fruits.

2.1. Obtention of the Cellulose Nanofibrils. The gelatinous cellulose nanofiber (CNF) from eucalyptus was obtained by a mechanical defibrillator (Grinder Supermasscoloider MKCA6-3; Masuko Sangyou Co., Ltda.) at a working speed of 1,700 rpm and $5 \mathrm{~A}$ electric current, according to the methodology described by Bufalino et al. [15] with same modifications. The nanofiber suspension obtained in the defibrillator was added to different chitosan concentration solutions after $24 \mathrm{~h}$ of stirring, and with the aid of an ultrasound, it was incorporated in different concentrations (3\% and 5\%) and then subjected to stirring for $1 \mathrm{~h}$. The films were obtained by the same methodology as described by Guimarães et al. [16, 17].

\subsection{Development of Chitosan/Cellulose Nanofiber} Bionanocomposites. For the preparation of the chitosan film forming formulations, a raw material from the Polymar Ind. Com. Import and Export LTDA Company was used. The preparation of the films was carried out by dispersing $1 \mathrm{~g}$ and $2 \mathrm{~g}$ of chitosan in $100 \mathrm{~mL}$ of glacial acetic acid (Chromate Chemicals Ltd.; Ref. no.: 1,010,352) 1\% ( $v / v)$. The solution was maintained under constant agitation for $24 \mathrm{~h}$. The films were obtained by the casting method $[16,17]$. Different concentrations ( $1 \%$ and $2 \%$ of chitosan) were uniformly poured on Petri dishes and dried at room temperature for $16 \mathrm{~h}$.

2.2.1. Color Analysis. The biodegradable films were subjected to color analysis, using the CIELAB: $L^{*} a^{*} b^{*}\left(L^{*}=\right.$ lightness, range from 0 (black) to 100 (white), $a^{*}=$ variance in the green/red axis $\left(-a^{*} / a^{*}\right)$, and $b^{*}=$ variance in the blue/yellow axis $\left.\left(-b^{*} / b^{*}\right)\right)$, determined in Konica Minolta CM-5 with an observation angle of $10^{\circ}$ and the D65 illuminant. The color variation $(\Delta E)$ was calculated according to

$$
\Delta E=\left[\left(\Delta L^{*}\right)^{2}+\left(\Delta a^{*}\right)^{2}+\left(\Delta b^{*}\right)^{2}\right]^{1 / 2},
$$

where $\Delta L^{*}=L^{*}-L_{0}^{*} ; \Delta a^{*}=a^{*}-a_{0}^{*}$; and $\Delta b^{*}=b^{*}-b^{*}$.
2.2.2. Film Thickness. The thickness of the samples was measured with the aid of a hand micrometer (Mitutoyo 102217). The thickness measurement used was the average of 6 measurements taken randomly at various points on the film.

2.2.3. Water Vapor Permeability (WVP). The water vapor permeability (WVP) of the elaborated films was determined using the 96-80 standard from ASTM, adapted by Guimarães et al. [17].

2.2.4. Scanning Electron Microscopy (SEM). Film micrographs were generated in a Leo Evo 40XVP scanning electron microscope (Carl Zeiss, Oberkochen, Germany). The images were generated by secondary electrons accelerated at a $20 \mathrm{kV}$ voltage and a working distance of $8 \mathrm{~mm}$.

2.2.5. Statistics. The results were submitted to analysis of variance, and the averages, where relevant, were subjected to the Tukey test at $5 \%$ probability, using the computational package SISVAR.

2.3. Coating of Strawberries with Bionanocomposites. "Camarosa" strawberries were harvested and purchased the same day, in the city of Barbacena/MG, Brazil, and transported under refrigeration to the Federal University of Lavras. They were then selected according to the absence of microbiological contamination and mechanical damage, size uniformity, and color (3/4 red). The strawberries were sanitized in a $50 \mathrm{mg} \cdot \mathrm{L}^{-1}$ sodium hypochlorite solution.

The strawberries were randomly distributed into 4 groups. Three groups were coated with different formulations of coating selected according to the results of the first stage of the experiment (2 groups were treated with $1 \%$ chitosan plus $3 \%$ and $5 \%$ CNF and the others with only $1 \%$ chitosan). The strawberries were immersed in the filmogenic solutions for $30 \mathrm{~s}$ and stored in a cold room for complete drying of the coating. $150 \mathrm{~g}$ of fruit was then packed in polypropylene containers $(15 \times 11 \times 6 \mathrm{~cm})$ and stored at $1 \pm 1^{\circ} \mathrm{C}$. The strawberries were stored for 21 days, and analyses were performed every 3 days. The last group, which did not receive any treatment (control), was stored in the same way; however, its analysis was possible only up to the 15 th day, due to the high incidence of microbial contamination.

2.3.1. Mass Loss, Firmness, and Enzymatic Activity of Polygalacturonase $(P G)$. The mass loss of the fruit during storage was determined with a digital analytical balance taking into consideration the initial mass of the containers and the final mass. The results were expressed in percentage. The firmness was measured in a TA-XT2i model texturometer (Stable Micro Systems Ltd.), making 6 measurements per repetition, using the $\mathrm{P} / 2 \mathrm{~N}$ tip, with speeds of $4 \mathrm{~mm} \cdot \mathrm{s}^{-1}$ (before test), $2 \mathrm{~mm} \cdot \mathrm{s}^{-1}$ (during test), and $8 \mathrm{~mm} \cdot \mathrm{s}^{-1}$ (after test), the penetration depth of $5 \mathrm{~mm}$, the maximum load cell of $50 \mathrm{~kg}$, and the precision of $0.1 \mathrm{~g}$. The results were expressed in N. The enzymatic activity of polygalacturonase (PG) was determined according to Markovic et al. [18]. Enzyme activity was expressed in UAE $\min ^{-1} \cdot \mathrm{g}^{-1}$ of fruit. 
2.3.2. Color Analysis. The coloration $\left(L^{*}, a^{*}, b^{*}, h^{\circ}\right.$, and $\left.C^{*}\right)$ was determined using a Minolta CR-400 colorimeter, making 10 readings per repetition.

2.3.3. Titratable Acidity, $p H$, and Soluble Solids. The determination of titratable acidity (TA) was performed by titration with $\mathrm{NaOH}$ solution, and the $\mathrm{pH}$ was determined by a $\mathrm{pH}$ meter (Tecnal TEC-3MP). The soluble solids were obtained by refractometry in a digital refractometer (Reichert AR200) [19].

2.3.4. Preparation of the Extract for Analysis of Vitamin C. Approximately $5 \mathrm{~g}$ of the sample was grounded in $45 \mathrm{ml}$ of $5 \%$ oxalic acid and homogenized on a shaker table (MOD.109, Nova Ética) at $130 \mathrm{rpm}$ for $30 \mathrm{~min}$. The extract was stored under refrigeration until analysis.

2.3.5. Preparation of the Extract for the Analysis of Antioxidant Activity of Total Phenolic Content. For extraction, we used the methodology described by Rufino et al. [20-22]. Approximately $2.5 \mathrm{~g}$ of the triturated sample was mixed in $20 \mathrm{ml}$ of $50 \%$ methanol and allowed to stand for $1 \mathrm{~h}$ at room temperature. After this period, the mixture was centrifuged at $14,000 \mathrm{rpm}$ for $15 \mathrm{~min}$, and the supernatant was collected. $20 \mathrm{ml}$ of $70 \%$ acetone was added to the residue and allowed to stand for $1 \mathrm{~h}$ at room temperature. After this period, the mixture was centrifuged at $14,000 \mathrm{rpm}$ for $15 \mathrm{~min}$. The supernatant was then collected and added to the first supernatant, and the volume was adjusted to $50 \mathrm{ml}$ using distilled water. The strata and extract were stored under refrigeration until analysis.

2.3.6. Quantification of the Vitamin C, Total Phenolic Content, Total Anthocyanin Content, and Enzymatic Activity of Phenylalanine Ammonia Lyase (PAL). The quantification of the vitamin $\mathrm{C}$ concentration was performed by the colorimetric method, with results expressed in mg of ascorbic acid per $100 \mathrm{~g}$ of the fruit, according to Strohecker and Henning [23]. The determination of total phenolic content was performed according to Waterhouse [24], and the results were expressed in $\mathrm{mg}$ of gallic acid equivalent (GAE) per $100 \mathrm{~g}$. The total anthocyanin content was quantified following the differential $\mathrm{pH}$ method, proposed by Giusti and Wrolstad [25]. The monomeric anthocyanin (MA) was calculated as cyanidin-3-glucoside $(\mathrm{MW}=449.2)$, and the results were expressed in $\mathrm{mg} 100 \mathrm{~g}^{-1}$ of the fruit, using the following formula:

$$
\operatorname{AM}\left(\mathrm{mg} \cdot 100 \mathrm{~mL}^{-1}\right)=\frac{(A \times \mathrm{PM} \times \text { dilution factor } \times 100)}{\varepsilon(26900) \times 1},
$$

where $A=$ absorbance and $\varepsilon=$ molar absorptivity.

The phenylalanine ammonia lyase (PAL) activity was estimated by the method described by Hyodo et al. [26] with modifications and expressed in enzyme activity units per minute per gram of fruit (UAE $\mathrm{min}^{-1} \cdot \mathrm{g}^{-1}$ of fruit).
2.3.7. Antioxidant Activity. The antioxidant activity was calculated by three methods: ABTS, DPPH expressed as EC50, and the autoxidation of the beta-carotene/linoleic acid system. The antioxidant capacity by reduction of the $\mathrm{ABTS}^{\bullet+}$ free radical was determined according to the method modified by Rufino et al. [20] with results expressed in $\mu \mathrm{M}$ trolox per $\mathrm{g}$ of fruit.

For the DPPH method, the methodology of Rufino et al. [21] was adopted, with results expressed as EC50, which represents the amount of antioxidant to reduce the initial concentration of DPPH by $50 \%$.

For the beta-carotene/linoleic acid system quantification, the methodology modified by Rufino et al. [22] was adopted. The results may be expressed according to the following formulas:

$$
\begin{aligned}
& \% \text { oxidation }=\frac{[(\text { Abs reduction }) \text { samples } \times 100]}{(\text { Abs reduction }) \text { system }}, \\
& \% \text { protection }=100-(\% \text { oxidation })
\end{aligned}
$$

2.3.8. Fungal Deterioration. Evaluation of fungal deterioration was done by visual assessment. Strawberries that had mycelial growth on the surface were considered contaminated. The results were expressed as a percentage of fruits not suitable for consumption and/or contaminated strawberries.

2.3.9. Statistics. The experiment was carried out in a completely randomized experimental design $(8 \times 4)$, with eight storage times $(0,3,6,9,12,15,18$, and 21 days $)$ and 4 treatments (three film formulations and control) with three repetitions, and the experimental unit consists of a $150 \mathrm{~g}$ tray. The results were submitted to analysis of variance, and the averages, when significant, were compared by the Tukey test or submitted to a $5 \%$ probability polynomial regression, using the computational package SISVAR.

\section{Results and Discussion}

3.1. Characteristics of Different Film Formulations. The color, thickness, and water vapor permeability (WVP) variables for each film formulation are given in Table 1 . These variables are important in determining the film quality. Although transparency is closely linked to the acceptance of biodegradable films in the market, since it allows better visualization of the coated food, thickness and WVP define the function and the food on which it should be applied.

We observed that the change in chitosan concentration was primarily responsible for the change in the $L^{*}$ and $b^{*}$ variables, which were not affected by the CNF. Increasing the concentration of chitosan led to a decrease of $L^{*}$ (lightness loss), which indicates a darker color in films with $2 \%$ chitosan, independent of CNF concentration. The $b^{*}$ coordinate increased with the increase in chitosan concentration. Chitosan has a yellow color, and thus, it was expected that the increase in its percentage would cause such a change. The variable $a^{*}$ did not change significantly, as a function of the 
TABLE 1: Color, thickness, and water vapor permeability for different film formulations.

\begin{tabular}{|c|c|c|c|c|c|c|c|}
\hline \multirow{2}{*}{$\begin{array}{l}\text { Chitosan } \\
\text { concentration }\end{array}$} & \multirow{2}{*}{$\begin{array}{c}\mathrm{CNF} \\
\text { concentration }\end{array}$} & \multicolumn{4}{|c|}{ Color } & \multirow{2}{*}{ Thickness $(\mu \mathrm{m})$} & \multirow{2}{*}{$\begin{array}{l}\text { Water vapor permeability } \\
\left(\mathrm{g} \cdot \mathrm{mm} / \mathrm{kPa} \cdot \mathrm{d} \cdot \mathrm{m}^{2}\right)\end{array}$} \\
\hline & & $L^{*}$ & $a^{*}$ & $b^{*}$ & $\Delta E$ & & \\
\hline $1 \%$ & \multirow[b]{2}{*}{$0 \%$} & $86.2^{b}$ & $-0.60^{\mathrm{a}}$ & $2.98^{\mathrm{a}}$ & - & $43.3^{\mathrm{a}}$ & $17.80^{\mathrm{c}}$ \\
\hline $2 \%$ & & $72.1^{\mathrm{a}}$ & $-0.64^{\mathrm{a}}$ & $5.84^{\mathrm{b}}$ & - & $46.2^{\mathrm{a}}$ & $18.23^{\mathrm{c}}$ \\
\hline $1 \%$ & \multirow{2}{*}{$3 \%$} & $86.3^{\mathrm{b}}$ & $-0.64^{\mathrm{a}}$ & $3.02^{\mathrm{a}}$ & 1.24 & $63.3^{\mathrm{b}}$ & $14.15^{\mathrm{b}}$ \\
\hline $2 \%$ & & $71.7^{\mathrm{a}}$ & $-0.60^{\mathrm{a}}$ & $6.08^{\mathrm{b}}$ & 1.31 & $65.3^{\mathrm{b}}$ & $13.62^{\mathrm{b}}$ \\
\hline $1 \%$ & \multirow{2}{*}{$5 \%$} & $85.4^{\mathrm{b}}$ & $-0.60^{\mathrm{a}}$ & $2.93^{\mathrm{a}}$ & 1.40 & $87.4^{\mathrm{c}}$ & $12.64^{\mathrm{ab}}$ \\
\hline $2 \%$ & & $72.3^{\mathrm{a}}$ & $-0.62^{\mathrm{a}}$ & $5.93^{\mathrm{b}}$ & 1.27 & $86.6^{\mathrm{c}}$ & $11.87^{\mathrm{a}}$ \\
\hline
\end{tabular}

*Averages followed by the same letter in the column do not differ statistically by the Tukey test, at $5 \%$ probability.

analyzed treatments. Regarding the changes in $\Delta E$, we observed that variations between formulations with and without CNF were very small, almost irrelevant, indicating that the addition of CNF causes minimal changes in the visual aspect of the film. Our results for the color coordinates are similar in behavior to those of Casariego et al. [27], who also worked with chitosan films. However, as to the magnitude of results, Casariego et al. obtained a value of 9.66 for the $b^{*}$ coordinate for films containing $1 \%$ chitosan and 12.76 for films with $2 \%$ chitosan, superior than those observed. That difference between studies can be explained by several factors, such as the type of acid used in the preparation of the film and its concentration, as well as the properties of the chitosan and other components of the film.

In the concentrations used, the chitosan did not interfere with film thickness and WVP, although an increase and a decrease, respectively, in these variables were observed in response to the CNF addition (Table 1). Films with higher CNF (5\%) concentration presented higher thickness and lower permeability values, despite the concentration of chitosan used. The CNF application is used in order to improve the barrier properties of biodegradable films; thus, this increase is seen as a major indication of this function. Jiménez et al. [28] state that, besides being appropriate to meet the functionality requirements, the thickness measurements should be homogeneous throughout the length of the film, thereby preventing possible defects in the conservation of the packaged product.

The high permeability (Table 1) of chitosan films without the CNF addition may be explained due to the hydrophilic character of the chitosan molecule, which causes the biodegradable films to not present a good moisture barrier. The chitosan molecules contain polar groups in their structure which are capable of binding with environment water through hydrogen bonding. This increase in water vapor causes a series of interactions in the polymeric matrix which results in high gas permeation and water sorption [29].

In films with $1 \%$ chitosan studied by Wong et al. [30], WVP values were $3.1 \mathrm{~g} \cdot \mathrm{mm} / \mathrm{kPa} \cdot \mathrm{d} \cdot \mathrm{m}^{2}$, lower than those found here, and Suyatma et al. [31] obtained values of $15.6 \mathrm{~g} \cdot \mathrm{mm} / \mathrm{kPa} \cdot \mathrm{d} \cdot \mathrm{m}^{2}$, closer to the values found in this present work.

The lower WVP dictated by the CNF can be explained by the tortuous path concept; the CNF accumulation in the film creates a barrier to the passage of water molecules, which take a longer time to go through the path that was previously free, that is, CNFs are skillful at creating a zigzag, reducing liquid and gas diffusion. The permeability reduction is strongly related to the reduction in the coefficient of diffusion provided by the presence of micro/nanofibrils [32], which leads to improvement of the barrier to water vapor.

Micrographs of films with $1 \%$ and $2 \%$ chitosan and their CNF variations $(0 \%, 3 \%$, and $5 \%)$ are presented in Figure 1. Small clusters are observed in both chitosan formulations (Figures 1(a) and 1(b)), due to inefficient extraction of the polysaccharide used as a matrix.

When there is a $3 \% \mathrm{CNF}$ addition to both chitosan concentrations (Figures 1(c) and 1(d)), the occurrence of nanofibril bundles throughout the polymeric matrix is observed. The same dispersion pattern can be observed in Figures 1(e) and 1(f) with the addition of $5 \%$ nanofibrils, along with the significant increase of CNF bundles. The micrographs confirm the differences in thickness and water vapor permeability discussed in Table 1.

3.2. Coating of Strawberries with Bionanocomposites. Given the above formulations, treatments chosen for application on the strawberry in the second step of the experiment were $1 \%$ chitosan, $1 \%$ chitosan $+3 \% \mathrm{CNF}$, and $1 \%$ chitosan $+5 \%$ $\mathrm{CNF}$, since the addition of nanofibers proved to be effective for improving the film barrier and mechanical properties and the lowest concentration of chitosan exhibited a more transparent film.

Significant differences in strawberry mass loss occurred due to the interaction between the coatings and storage time (Figure 2). There was a linear increase in mass loss in all fruits, being more pronounced in control fruits. The mass loss of the coated fruit was significantly lower than that of control fruits throughout storage, and the treatment with the highest CNF concentration showed the lower mass loss, followed by the formulation with $3 \% \mathrm{CNF}$ and without $\mathrm{CNF}$ addition, which proves chitosan effectiveness, increased by the CNF, in reducing the mass loss percentage during storage.

The main form of mass loss in fruits and vegetables is by respiration and transpiration; both mechanisms are minimized by the chitosan coating, which modifies the internal atmosphere of the fruit and prevents the exchange of gases with the outer atmosphere. With the reduced metabolism, fruits coated with chitosan tend to lose less mass than the uncoated fruit. It is known that CNFs are responsible for creating a zigzag in the film structure, which would hinder the passage of permeants such as $\mathrm{O}_{2}, \mathrm{CO}_{2}$, and water vapor $[33,34]$. Figure 2 clearly demonstrates the CNF influence in 

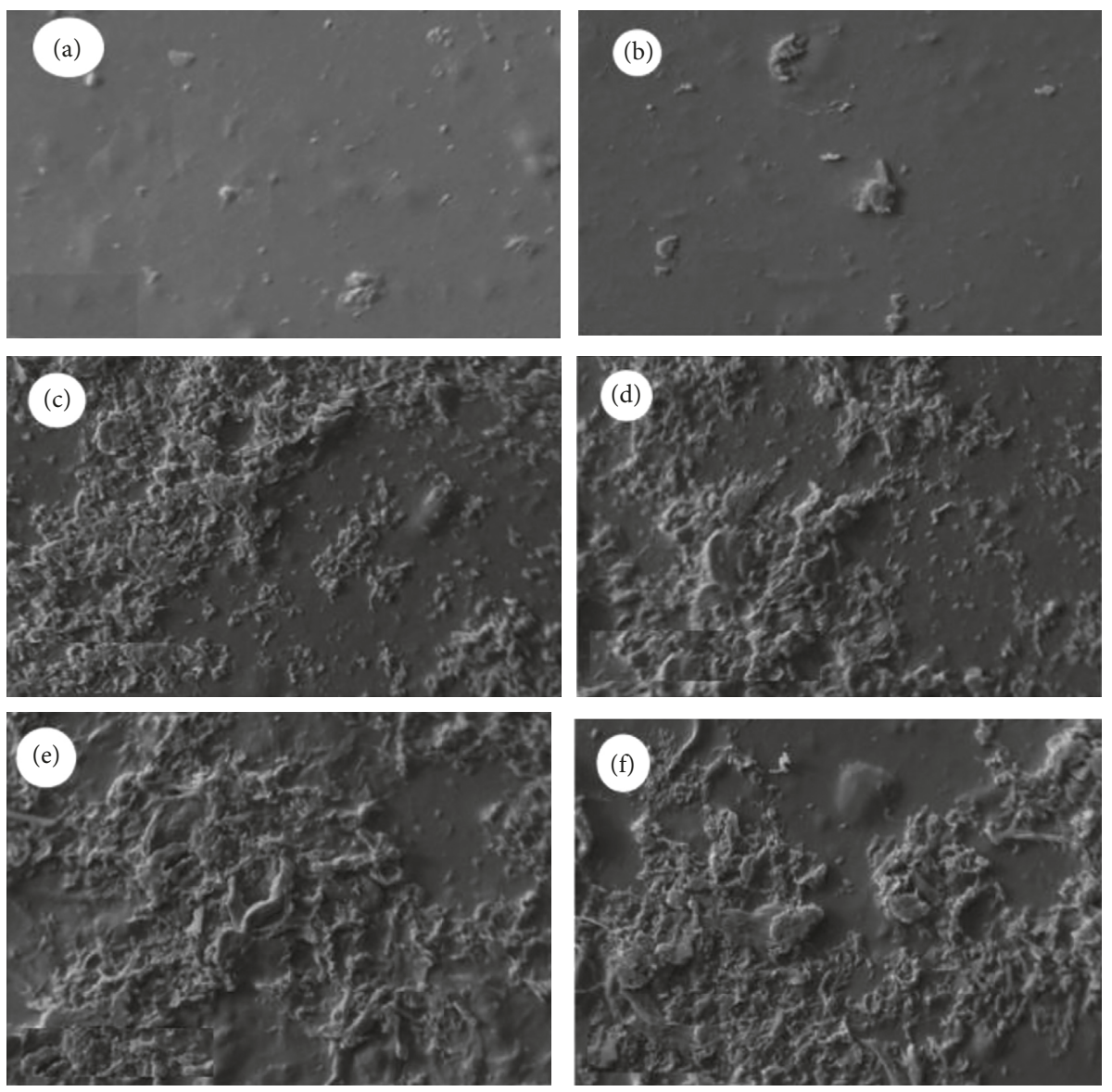

FIGURE 1: Scanning electron microscope (SEM) micrographs of chitosan films (1\% and $2 \%)$ with cellulose nanofibers (0\%, 3\%, and 5\%): (a) film with $1 \%$ chitosan; (b) film with $2 \%$ chitosan; (c) film with $1 \%$ chitosan $+3 \%$ CNF; (d) film with $2 \%$ chitosan $+3 \%$ CNF; (e) film with $1 \%$ chitosan $+5 \%$ CNF; and (f) film with $2 \%$ chitosan $+5 \%$ CNF.

reducing mass loss, which is probably due to tortuosity generated by the nanoparticles [35].

Similar results have been described in the literature. Ribeiro et al. [36] applied chitosan and carrageenan coating on strawberries stored for 6 days under refrigeration $\left(4^{\circ} \mathrm{C}\right)$, achieving a mass loss of approximately $3 \%$ compared to the control at the end of the experiment. Hernández-Muñoz et al. [37] observed a mass loss between 14.2 and $19.6 \%$ in strawberries coated with chitosan and stored at $10^{\circ} \mathrm{C}$ for 7 days.

Significant interaction between coating and storage time was also observed for the firmness variable. There was a reduction of the strawberry firmness, more pronounced in the control fruits (Figure 2). The efficiency of chitosan, with or without CNF, in containing the softening, can be noticed from the 6th day of storage, compared to the control. The $\mathrm{CNF}$ association with chitosan proved to be effective from the 9th day of storage, although the effect, in general, was not dependent on the CNF concentrations studied (3\% and 5\%).

The strawberries' firmness tends to reduce during storage, and this occurs because of a series of reactions, even after the fruit harvest. The softening of the strawberry is attributed to the breakdown of the middle lamella of the parenchymal cells with slight changes in pectin molecular weight and small reduction in hemicellulose content [37].
Texture is an attribute of great relevance for the fruit purchase decision-making, so the firmer the fruit, the better its acceptance. The strawberry is a soft and delicate fruit and very susceptible to mechanical damage and microbiological contamination. The improvement of techniques to ensure a better texture for a longer time is needed in order to extend the life of this fruit. Thus, the coating of fruits with chitosan and CNF was effective in delaying their softening.

The strawberry softening, shown in Figure 2, is closely linked to the activity of polygalacturonase (PG), an enzyme responsible for pectin depolymerizing, which is a cell wall compound. In fact, there was an increase in PG activity in all strawberries, coated or not, which may be associated with the decrease in firmness (Figure 2). It is noticed that the PG activity was more intense in control fruits throughout storage, but the other treatments followed the same trend: lower activity in the initial days and increased activity at the end of the experiment. It is noteworthy that the control was the treatment with a greater decrease in fruit firmness, which reinforces the PG connection with the cell wall degradation. The CNF association with chitosan did not interfere with PG activity.

The reduction in softening of the fruits coated with chitosan (with and without CNF) can be attributed to the 


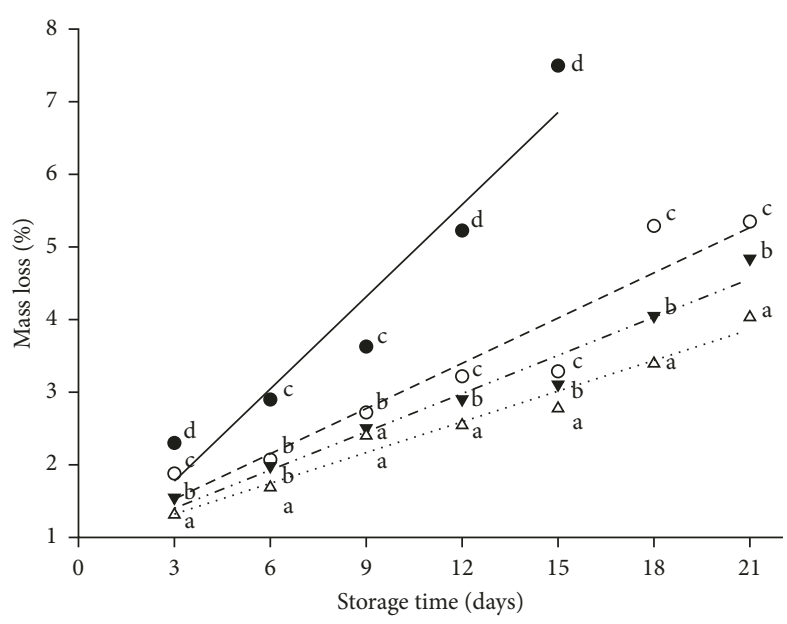

- Control

- $1 \%$ chitosan

v $1 \%$ chitosan $+3 \% \mathrm{CNF}$

$\Delta \quad 1 \%$ chitosan $+5 \% \mathrm{CNF}$

- Fitness control, $y=0.42 x+0.49, R^{2}=0.92$

- - . Fitness $1 \%$ chitosan, $y=0.20 x+0.91, R^{2}=0.90$

… Fitness $1 \%$ chitosan $+3 \%$ CNF, $y=0.17 x+0.90, R^{2}=0.96$

- - - Fitness 1\% chitosan $+5 \%$ CNF, $y=0.13 x+0.91, R^{2}=0.96$

(a)

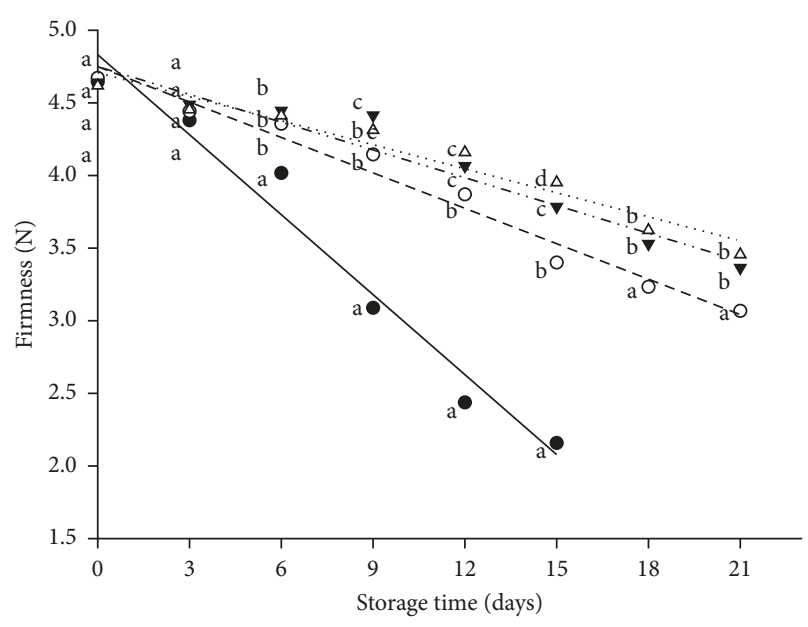

- Control

○ $1 \%$ chitosan

- $1 \%$ chitosan $+3 \% \mathrm{CNF}$

$\Delta \quad 1 \%$ chitosan $+5 \% \mathrm{CNF}$

Fitness control, $y=0.18 x+4.83, R^{2}=0.96$

- - . Fitness $1 \%$ chitosan, $y=0.08 x+4.75, R^{2}=0.97$

… Fitness $1 \%$ chitosan $+3 \%$ CNF, $y=0.06 x+4.72, R^{2}=0.97$

- - Fitness $1 \%$ chitosan $+5 \%$ CNF, $y=0.05 x+4.72, R^{2}=0.96$

(b)

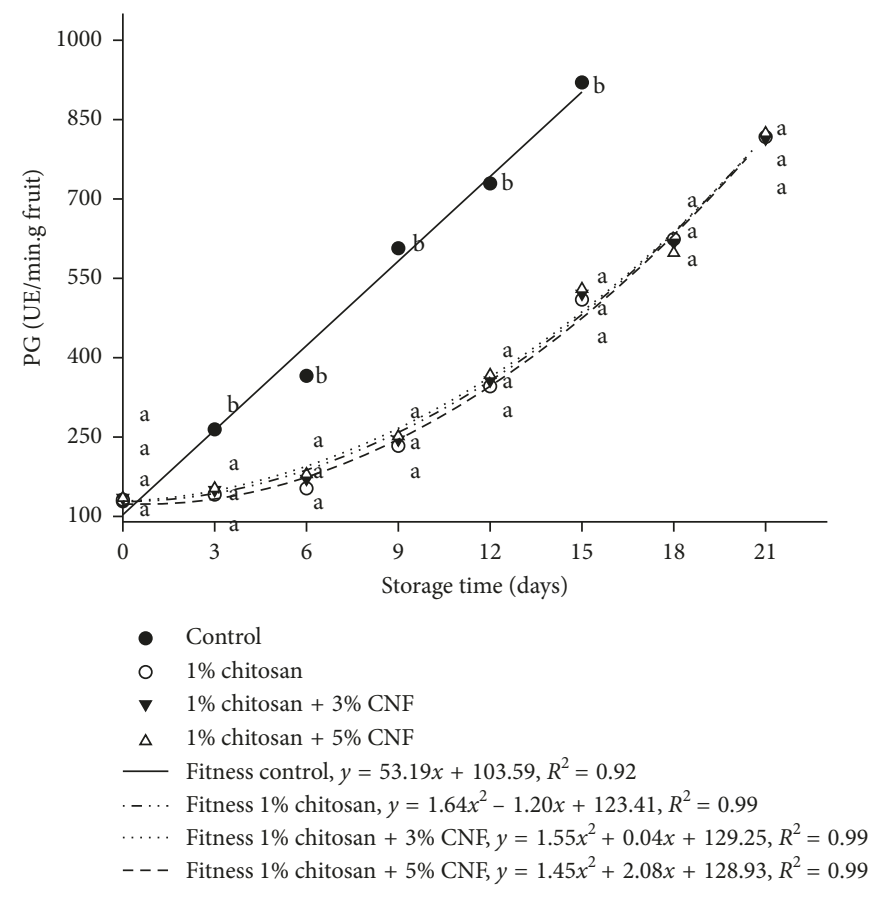

(c)

Figure 2: Mass loss, firmness, and polygalacturonase (PG) activity in strawberries stored for 21 days at $1^{\circ} \mathrm{C}$ with and without coating. Same letters in the same storage time denote that averages do not differ by the Tukey test at $5 \%$ significance.

characteristics of this polysaccharide. The negative charge on the chitosan molecule makes it susceptible to covalent bonds with the pectin in the fruit wall, forming the pectinchitosan complex and preventing the access of pectolytic enzymes [38].

Regarding the coloration, there was a linear decrease in $L^{*}, C^{*}$, and $h^{\circ}$ in all fruits, being more pronounced in control fruits (Figure 3). Significant differences between the control and the other treatments can be observed from the 6th day of storage for the $L^{*}$ value and the 3rd day of storage for $h^{\circ}$ and $C^{*}$, remaining that way until the end of the experiment. The fruits coated with chitosan, with or without CNF, did not differ, except for a difference observed only at the 18th day of storage for $C^{*}$. 


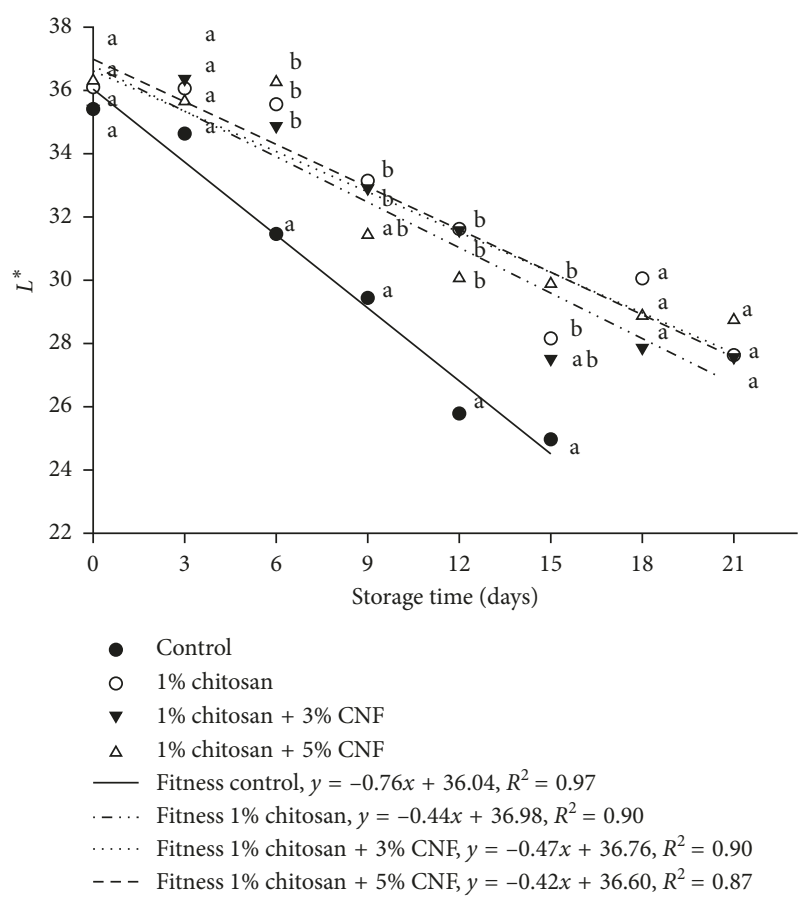

(a)

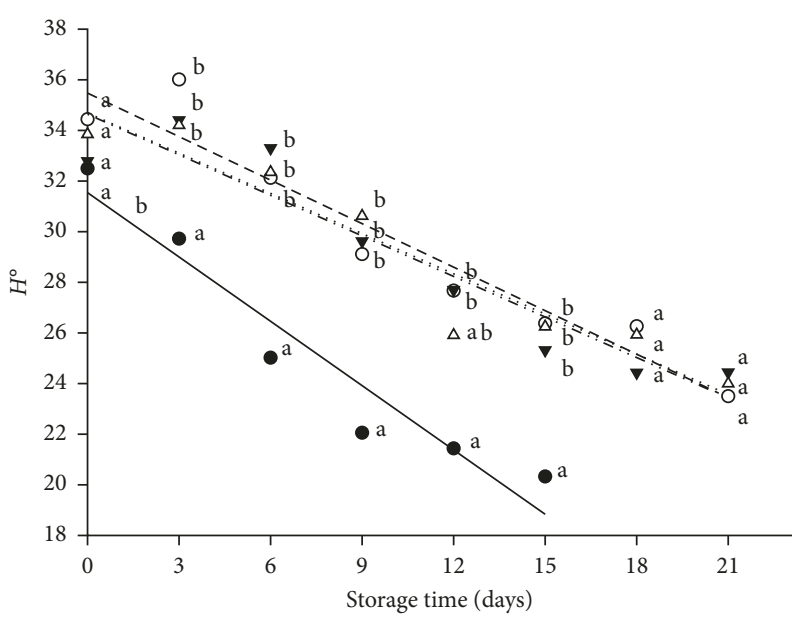

- Control

- $1 \%$ chitosan

v $1 \%$ chitosan $+3 \% \mathrm{CNF}$

$\triangle 1 \%$ chitosan $+5 \% \mathrm{CNF}$

Fitness control, $y=-0.84 x+31.51, R^{2}=0.92$

- - . F Fitness $1 \%$ chitosan, $y=-0.57 x+35.44, R^{2}=0.92$

… Fitness $1 \%$ chitosan $+3 \%$ CNF, $y=-0.53 x+34.60, R^{2}=0.89$

- - Fitness $1 \%$ chitosan $+5 \%$ CNF, $y=-0.52 x+34.69, R^{2}=0.91$

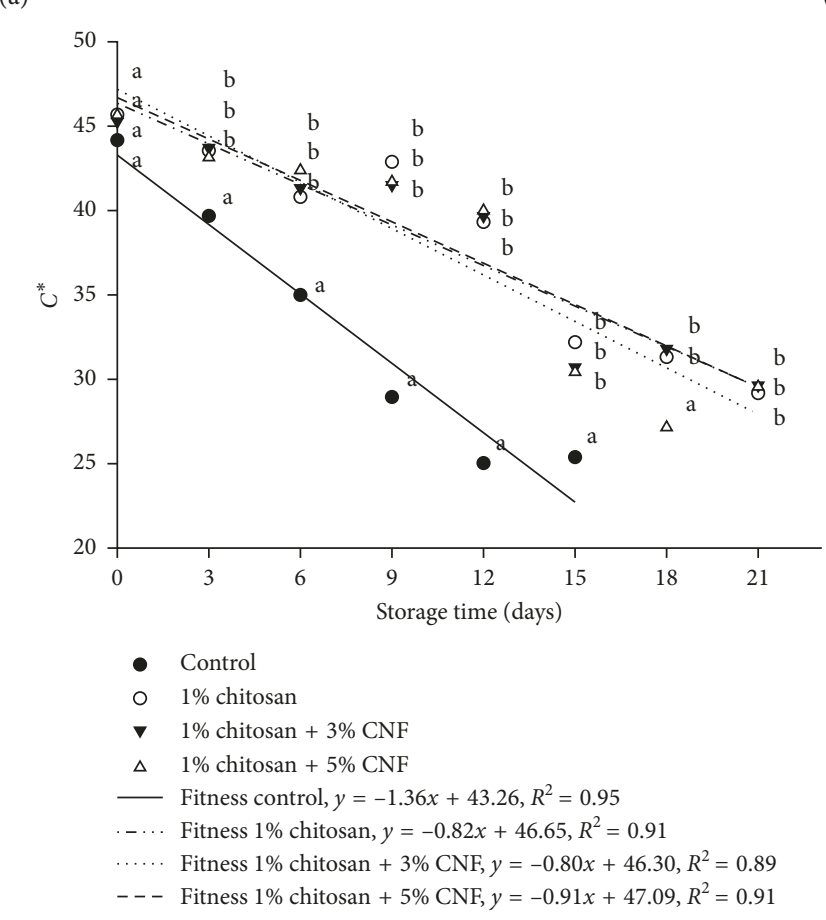

(b)

Figure 3: Average values of $L^{*}, h^{\circ}$, and $C^{*}$ of coated and uncoated strawberries. Same letters in the same storage time denote that averages do not differ by the Tukey test at $5 \%$ significance.

According to the CIELAB system, the $L^{*}$ value is associated with how light or dark the fruit is, that is, the lighter the fruit, the higher the value, whereas the $h^{\circ}$ and $C^{*}$ parameters are connected to hue and color purity, respectively. Therefore, the reduction of these variables during storage suggests redness, darkening, and loss of color purity, which is consistent with what has been previously discussed that reactions continue to occur even after the harvest, for example, the anthocyanin biosynthesis, which turns the fruit redder and darker. Strawberries treated with biodegradable film had their metabolism slowed, delaying the anthocyanin biosynthesis and fruit coloration alterations.

$\mathrm{pH}$, titratable acidity, and soluble solids of coated and uncoated strawberries can be seen in Figure 4. The $\mathrm{pH}$ and 


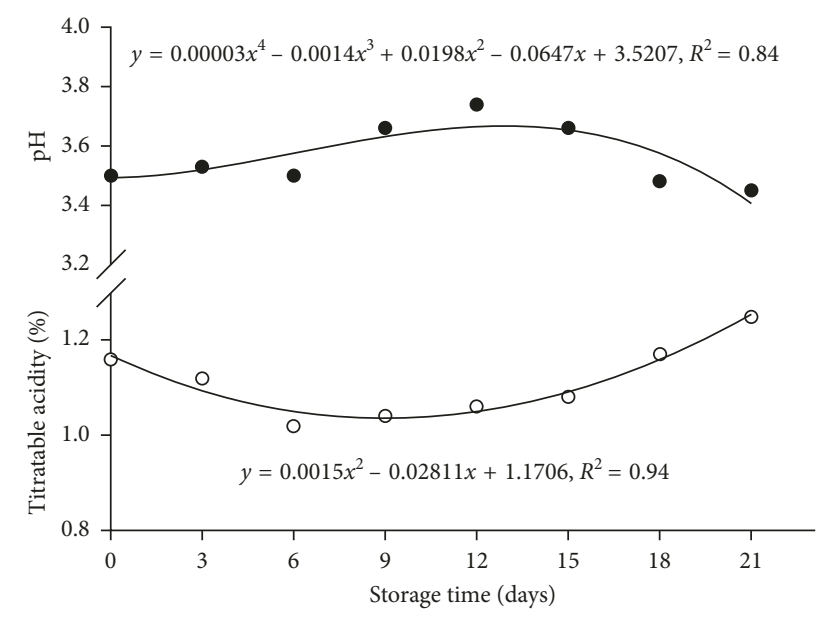

(a)

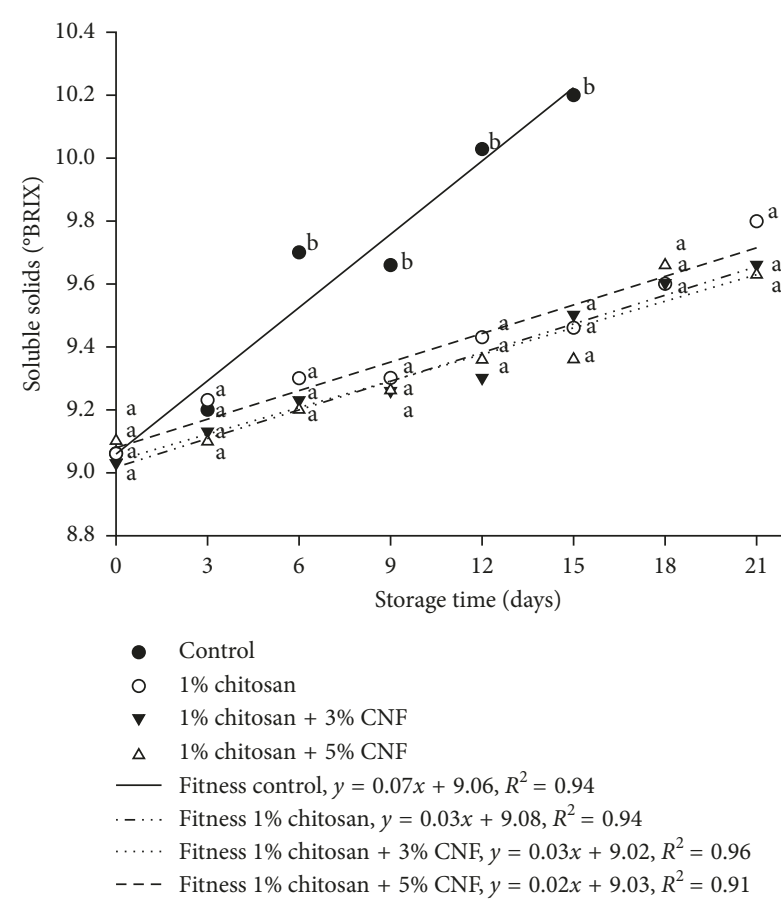

(b)

FIgURE 4: Average values of $\mathrm{pH}$, titratable acidity, and soluble solids of strawberries throughout 21 days of storage. Same letters in the same storage time denote that averages do not differ by the Tukey test at $5 \%$ significance level.

titratable acidity varied significantly during storage, although they were not influenced by the coating. $\mathrm{A} \mathrm{pH}$ decrease followed by an increase was accompanied by an increase followed by a decrease of acidity, as was expected.

Hernández-Muñoz et al. [37] report that strawberries without the chitosan film tend to slightly increase the $\mathrm{pH}$ during storage. Elevation of the $\mathrm{pH}$ was observed in the strawberries in the present study, despite the use of the coating.

Unlike the $\mathrm{pH}$ and titratable acidity, soluble solids (Figure 4) were interactively affected by the coatings and storage time. There was a linear increase in this variable during storage, being more pronounced in control fruits. Significant differences between control and coated fruits can be observed from the 6th day of storage, although no difference was observed when comparing the coatings with each other. The significant increase in the control treatment was probably due to greater moisture loss from this treatment. It is known that the main cause of mass loss is the fruit water loss, which can lead to a significant soluble solid accumulation. Indeed, the control fruits showed greater mass loss than the coated fruits (Figure 2), as discussed above.

The results for the soluble solids found here are comparable to those reported by Vargas et al. [39], who also studied strawberries with and without chitosan coating. Tanada-Palmu and Grosso [40] reported increased soluble solids in strawberries without coatings and also attributed this to greater loss of moisture during storage.

The vitamin $\mathrm{C}$ concentration (Figure 5(a)) decreased linearly in strawberries, during storage, regardless of treatment. It is observed that the control fruits presented a sharper decrease, presenting less than half of the initial concentration on the 15 th day. The coated fruits showed the same behavior as the control but with less variation during the 21 days of storage. The coating with chitosan determined higher vitamin $\mathrm{C}$ retention from the 9th day of storage, and no difference was observed due to the cellulose nanofiber application. The decrease of ascorbic acid is consistent with the decline in strawberries treated with chitosan reported by Amal et al. [41]. Amal et al. state that the chitosan formulations reduce oxygen diffusion, slow respiration, and delay the ascorbic acid oxidation reaction in fruits. Stress and mass loss reported in Figure 2 can also contribute to vitamin $\mathrm{C}$ degradation acceleration.

The total phenolic concentration decreased linearly throughout storage (Figure 5(a)). Control fruits had a lower concentration of total phenolics at 3, 12, and 15 days, compared to those coated with $1 \%$ chitosan $+5 \% \mathrm{CNF}$, and only at 12 days when compared to those coated with $1 \%$ chitosan and $1 \%$ chitosan $+3 \%$ CNF.

Thus, there is a greater efficiency of the application of the coatings in the containment of the total phenolic content, compared to the control. However, when comparing the different nanofiber concentrations among themselves, excluding the control, no difference was observed. The reduction of phenolic compounds was expected over time, since the fruit cells collapse during the senescence period. The lower reduction in the strawberries treated with chitosan coating can be assigned to the semipermeable barrier that is formed. This barrier is able to reduce the external oxygen supply that would be used for the oxidation of phenolic compounds.

A quadratic behavior was observed for anthocyanins during the strawberry storage, with an increase followed by a decline (Figure 5(b)). The decrease in control fruits began on the 3rd day, while the decrease in fruits coated with chitosan began on the 9th day. A comparison of the means reveals higher concentrations of anthocyanins in the coated fruit compared to the control, after 12 days of storage. These results suggest a beneficial effect of the coating in maintaining the main strawberry pigment during storage. The different CNF concentrations did not interfere differently in anthocyanin content. 

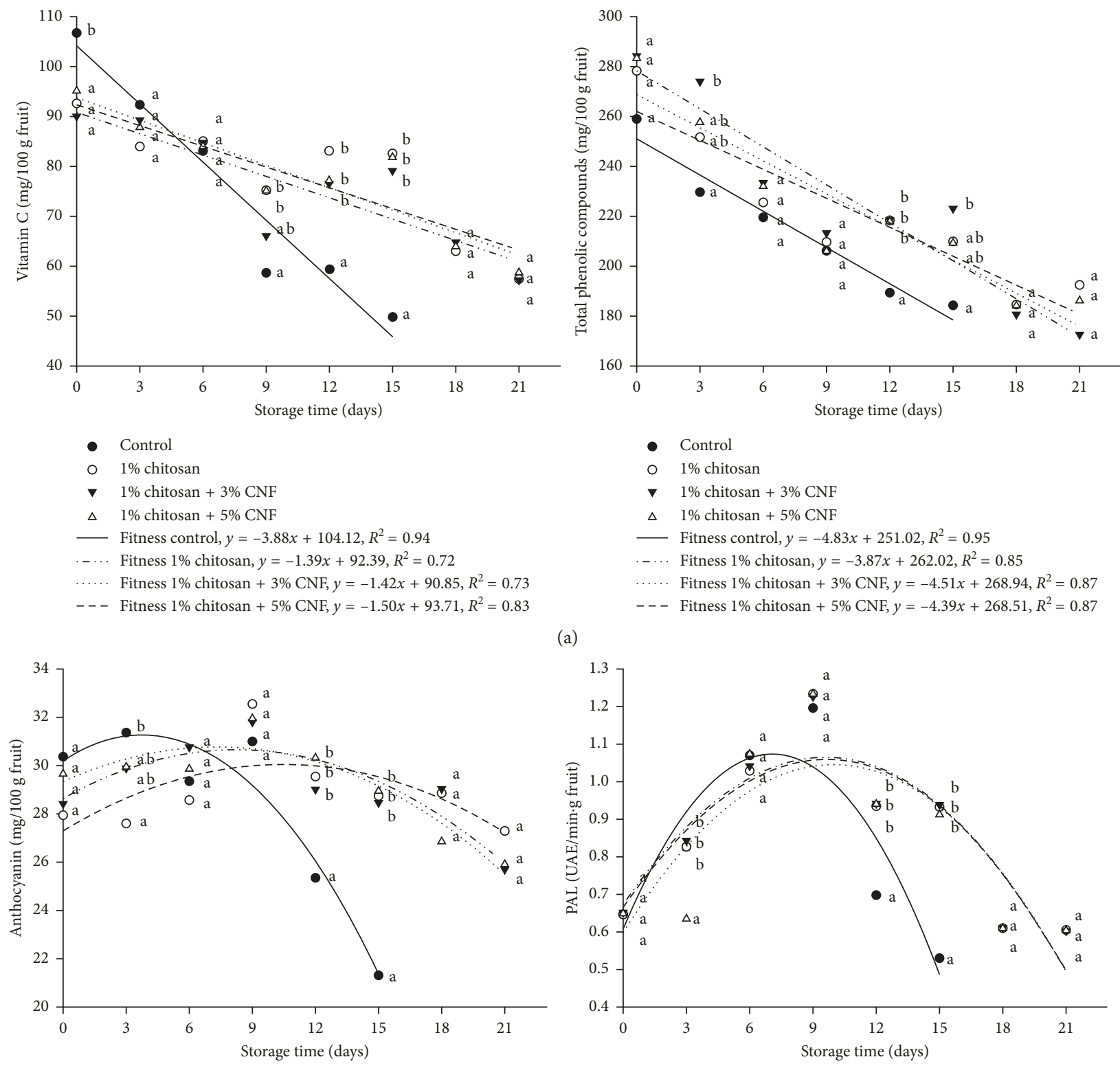

(a)

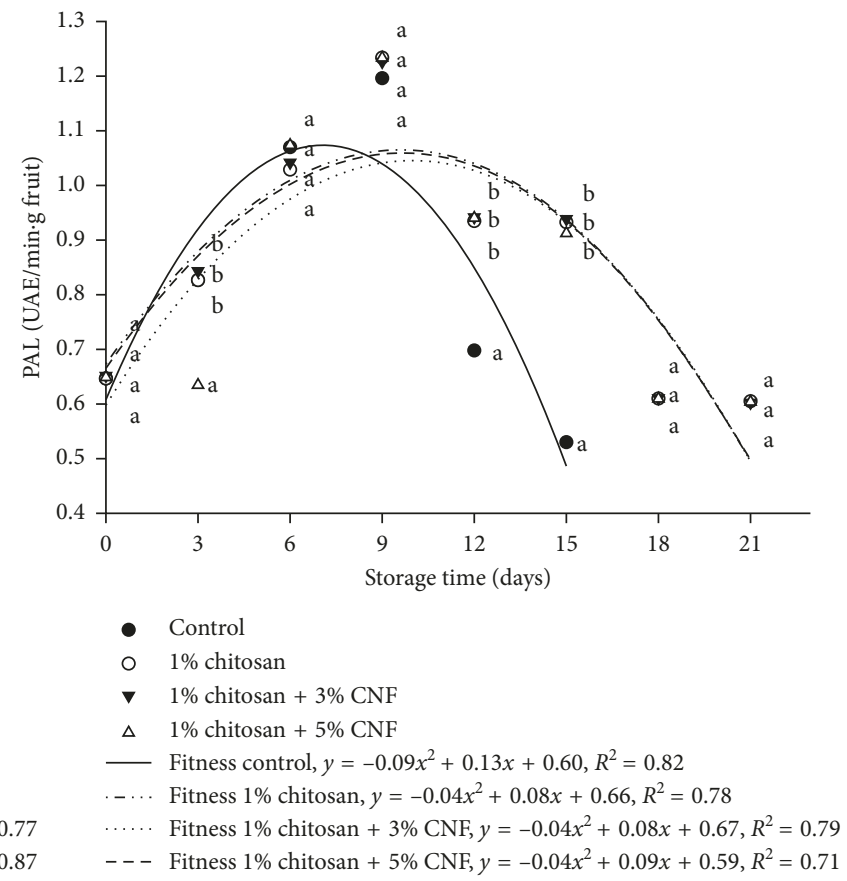

(b)

FIGURE 5: Changes in vitamin C content and phenolic compounds (a) and anthocyanin concentration and PAL activity (b) throughout strawberry storage with and without chitosan film. Same letters in the same storage time denote that averages do not differ by the Tukey test at $5 \%$ significance.

The anthocyanin concentrations in strawberries follow a trend that depends on several factors, including the temperature. Thus, different reports about the concentration of these compounds can be seen in the literature. Strawberries stored at temperatures above $0^{\circ} \mathrm{C}$ tend to increase the concentration of antioxidant compounds, as well as the concentration of total anthocyanins [42], whereas their degradation can be associated with oxidative processes that may occur due to stress caused by the loss of water over time. Moisture loss can possibly trigger damage to the plasma membrane and the cell wall of the fruit, promoting a decrease in the concentrations of this pigment. 

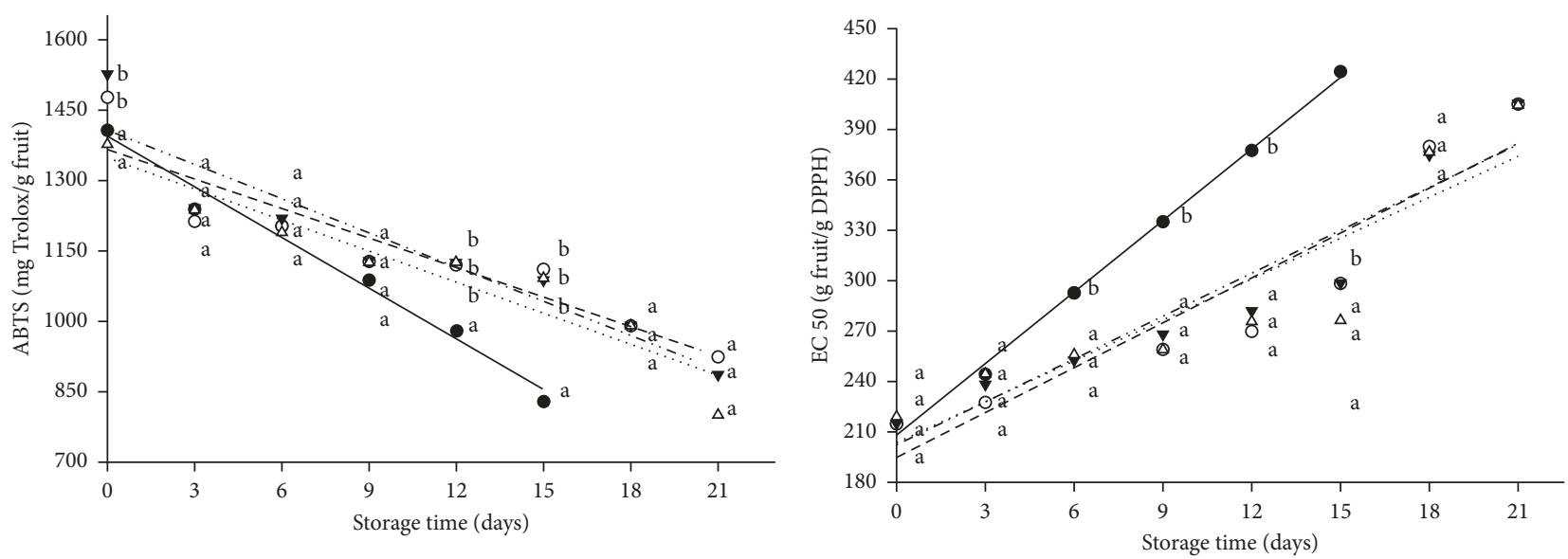

○ $1 \%$ chitosan

v $1 \%$ chitosan $+3 \%$ CNF

$\Delta \quad 1 \%$ chitosan $+5 \%$ CNF

- Fitness control, $y=-35.96 x+1393.96 R^{2}=0.97$

. - . Fitness $1 \%$ chitosan, $y=-20.87 x+1365.36 R^{2}=0.85$

… Fitness $1 \%$ chitosan $+3 \%$ CNF, $y=-24.35 x+1406.52 R^{2}=0.87$

- - - Fitness $1 \%$ chitosan $+5 \%$ CNF, $y=-19.49 x+1332.70 R^{2}=0.93$

(a)

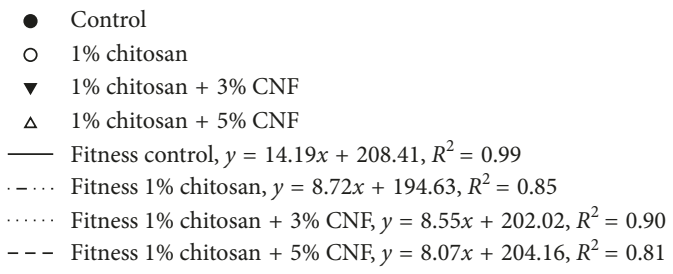

(b)

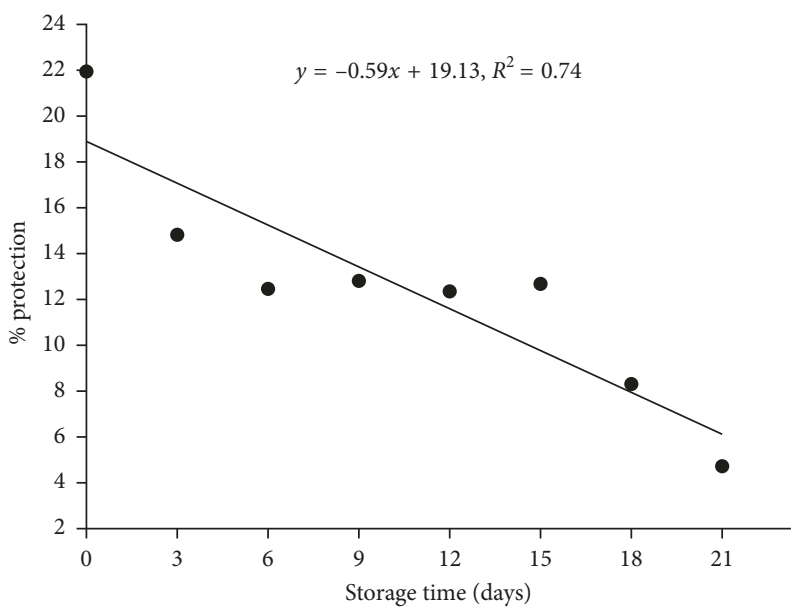

(c)

FIGURE 6: Strawberry antioxidant activity determined by the ABTS method (a), DPPH (EC50) method (b), and autoxidation of the betacarotene/linoleic acid system method (c) for fruits with and without edible coating. Same letters in the same storage time denote that averages do not differ by the Tukey test at $5 \%$ significance.

In a study conducted by Wang and Gao [42], in which strawberries were treated with different chitosan concentrations, higher concentrations of anthocyanin were observed in all treatments compared to the control. One of the hypotheses to explain this phenomenon was described by El Ghaouth et al. [43], who proposed that the chitosan film plays the role of a barrier, reducing water loss, modifying the endogenous $\mathrm{CO}_{2}, \mathrm{O}_{2}$, and ethylene, and delaying ripening and senescence. There are reports in the literature that biodegradable films are able to promote changes in the respiratory behavior of the fruit [44]. This fact can also be decisive in maintaining the characteristics of the fruit for a longer period of storage.
Quadratic behavior of the PAL activity was observed (Figure 5(b)) in the analyzed strawberries, despite the treatment applied. The PAL activity is directly linked with phenolic compound production, since it is the key enzyme in a number of routes, including anthocyanin synthesis. The fruits showed a peak of activity around the 9th day of storage, when the enzyme activity reached $1.2 \mathrm{UAE}$ $\min ^{-1} \cdot g^{-1}$ of fruit.

In the control fruits, there was a sharp decline from the 9th day onwards, while in the fruits coated with chitosan, with or without CNF, this most significant drop occured later (from the 15th day of storage). Treatments with chitosan can affect not only the PAL activity but also other fruit 


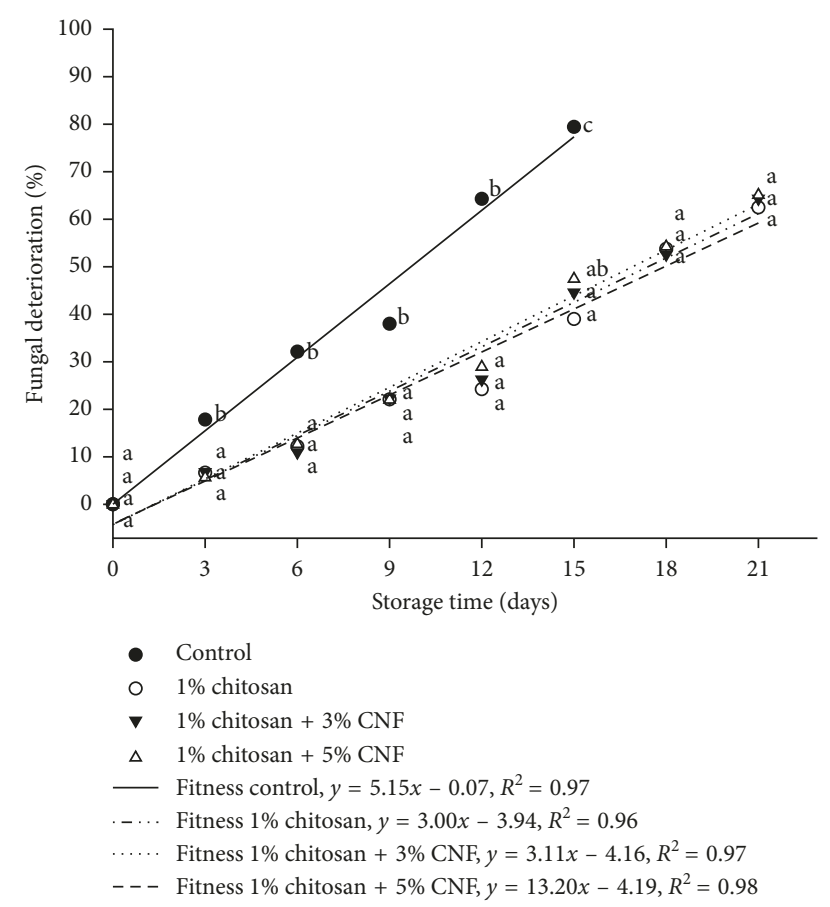

Figure 7: Average values in $\%$ of fungal contamination in strawberries with and without films during 21 days of storage. Same letters in the same storage time denote that averages do not differ by the Tukey test at $5 \%$ significance.

defense enzymes, which are associated with disease resistance [45].

Biosynthesis of phenolic compounds encompasses an extensive group of substances and involves a number of enzymes along the route. PAL is one of the first enzymes in the pathway responsible for the deamination of L-phenylalanine, transforming it into trans-cinnamic acid and ammonia. trans-Cinnamic acid can be incorporated into many different phenolic compounds (4-coumaric acid, caffeic acid, ferulic acid, and sinapic acid), but the biosynthesis of these compounds is complex and other products can originate along the route; for example, trans-cinnamate is used as a substrate for various pathways of secondary metabolism or for the production of volatile compounds through the use of 4-coumaroyl-CoA, both being intermediates of the phenylpropanoid route $[46,47]$. In addition, the PAL presents some isoforms that are capable of performing different functions and not directly linked to the production of phenolic compounds [48]. Thus, not all of the PAL activity described in Figure 5(b) should necessarily be seen in Figure 5(a).

The results of the antioxidant capacity of strawberries by the ABTS, DPPH (EC50), and autoxidation of the betacarotene/linoleic acid system methods are shown in Figure 6.

The antioxidant activity determined by ABTS (Figure 6(a)) indicates significant differences between control and coated fruits from the 12th day of storage onwards. The antioxidant capacity loss of the control strawberries was more pronounced than that of the coated strawberries, reaching half of the initial activity on the 15th day of the study. As for the DPPH
(Figure 6(b)), there was a linear increase in EC50 in all fruits examined, suggesting reduced antioxidant activity, more pronounced in control fruits, from the 6th day of storage.

Although chitosan has been effective in containing the loss of strawberry antioxidant potential, the different CNF concentrations associated with chitosan did not interfere with the antioxidant activity of the fruit in either methodology presented.

Wang and Gao [42], working with chitosan coating, detected a positive effect on the antioxidant potential of the treated strawberries. By the DPPH method, antioxidant activity reduction was observed in uncoated strawberries already on the 4 th day of storage. The strawberry antioxidant potential reduced about 3.5 times when compared to the treated strawberries. In the present study, less reduction was obtained; on the 12th day of storage, the treatments with coating had antioxidant activity, by the DPPH method (EC50), 2 times lower than that of the other treatments.

The autoxidation of the beta-carotene/linoleic acid system (Figure 6(c)) evaluated in this study does not show significant differences between control and coated fruits, regardless of formulation. Nevertheless, a gradual decrease in the protection percentage during storage has been verified.

Regarding the visual assessment (Figure 7), the control treatment presented almost $20 \%$ deterioration on the $3 \mathrm{rd}$ day, and after a week of storage, nearly $40 \%$ of the total volume of the tray analyzed showed signs of microbiological contamination. Strawberries coated with chitosan film, with and without $\mathrm{CNF}$, reached a similar contamination percentage (about $40 \%$ ) after 15 days of storage. Fungal decay is one of the main causes of postharvest loss in strawberry, along with inappropriate storage. Fungi are microorganisms with great capacity for colonization and can develop even at low temperatures [49].

The action of chitosan on fungi may be associated with the ability to change the function of the cell membrane of this microorganism. There are reports of permeability loss, metabolic disorders, and cell death [50]. Two key mechanisms are credited for the action of chitosan against microbial contamination: The first one concerns the direct interference in the pathogen development and the other one is the ability of the chitosan molecule to activate defense mechanisms in plant tissues [51].

Several studies in the literature report the efficiency of chitosan against various fungi, including Botrytis cinerea, the major strawberry contaminant. Brunel et al. [52] report the antimicrobial activity of chitosan in their work by dissolving the molecule in water, similar to the one performed in this work.

\section{Conclusions}

The chitosan concentration directly affects the color of the elaborated bionanocomposite. The association of CNF with chitosan improves the barrier and mechanical properties of the film. The development and application of chitosan/ cellulose nanofibril bionanocomposites were efficient in maintaining the postharvest quality of strawberries. The CNF 
in association with chitosan reduces "Camarosa" strawberry mass loss and softening. The CNF associated with chitosan at a $5 \%$ concentration is more effective than at $3 \%$ on strawberry mass loss reduction. The coating of the strawberry with $1 \%$ chitosan, regardless of association with the CNF, mitigates the changes of color, soluble solids, fungal contamination, vitamin C, total phenolics, anthocyanins, PAL activity, and antioxidant capacity. The present work contributes with important information on surface coating of fruits using cellulose nanofibrils. Further development of this approach could improve the performance of these coatings for the development of new and engineered solutions for packaging applications and quality of postharvest fruits.

\section{Conflicts of Interest}

The authors declare that they have no conflicts of interest.

\section{Acknowledgments}

The authors acknowledge the research funding agencies FAPEMIG, CNPq, and CAPES for the financial support received for this work.

\section{References}

[1] S. Kaur and M. Das, "Functional foods: an overview," Food Science and Biotechnology, vol. 20, no. 4, pp. 861-875, 2011.

[2] K. Aaby, S. Mazur, A. Nes, and G. Skrede, "Phenolic compounds in strawberry (Fragaria $\mathrm{x}$ ananassa Duch.) fruits: composition in 27 cultivars and changes during ripening," Food Chemistry, vol. 132, no. 1, pp. 86-97, 2012.

[3] C. I. G. L. Sarantópoulos and B. B. Moraes, "Embalagens ativas e inteligentes para frutas e hortaliças," Boletim de Tecnologia e Desenvolvimento de Embalagens, vol. 21, no. 1, p. 2, 2009.

[4] M. F. O. Prates and D. P. R. Ascheri, "Efeito da cobertura de amido de fruta-de-lobo e sorbitol e do tempo de armazenamento na conservação pós-colheita de frutos de morango," Boletim do Centro de Pesquisa e Processamento de Alimentos, vol. 29, no. 1, pp. 21-32, 2011.

[5] S. Seo, H. K. Ahn, J. Jeong, and J. Moon, "Consumers' attitude toward sustainable food products: ingredients vs. packaging," Sustainability, vol. 8, no. 10, p. 1073, 2016.

[6] L. Fernández-de Castro, M. Mengíbar, Á. Sánchez et al., "Films of chitosan and chitosan-oligosaccharide neutralized and thermally treated: effects on its antibacterial and other activities," LWT-Food Science and Technology, vol. 73, pp. 368-374, 2016.

[7] C. S. Miranda, R. P. Fiuza, J. Oliveira, R. F. Carvalho, D. H. Guimarães, and N. M. José, "Thermal, mechanical and morphological properties of composites developed from glycerol and dicarboxylic acids reinforced with piassava fiber," Macromolecular Symposia, vol. 319, no. 1, pp. 74-82, 2012.

[8] A. Patra, D. K. Bisoyi, P. K. Manda, and A. K. Singh, "Electrical and mechanical properties of the potassium permanganate treated short sisal fiber reinforced epoxy composite in correlation to the macromolecular structure of the reinforced fiber," Journal of Applied Polymer Science, vol. 128, no. 2, pp. 1011-1019, 2013.

[9] Q. Chaudhry, L. Castle, and R. Watkins, Nanotechnologies in Food, Royal Society of Chemistry, London, UK, 2017.
[10] B. Braun, J. R. Dorgan, and L. O. Hollingsworth, "Supramolecular ecobionanocomposites based on polylactide and cellulosic nanowhiskers: synthesis and properties," Biomacromolecules, vol. 13, no. 7, pp. 2013-2019, 2012.

[11] K. Li, J. Huang, H. Gao et al., "Reinforced mechanical properties and tunable biodegradability in nanoporous cellulose gels: poly(l-lactide-co-caprolactone) nanocomposites," Biomacromolecules, vol. 17, no. 4, pp. 1506-1515, 2016.

[12] N. Herrera, H. Roch, A. M. Salaberria et al., "Functionalized blown films of plasticized polylactic acid/chitin nanocomposite: preparation and characterization," Materials and Design, vol. 92, pp. 846-852, 2016.

[13] S. Shankar and J. W. Rhim, "Polymer nanocomposites for food packaging applications," in Functional and Physical Properties of Polymer Nanocomposites, A. Dasari and J. Njuguna, Eds., pp. 29-55, Wiley, New York, NY, USA, 2016.

[14] Q. Yang, T. Saito, L. A. Berglund, and A. Isogai, "Cellulose nanofibrils improve the properties of all-cellulose composites by the nano-reinforcement mechanism and nanofibril-induced crystallization," Nanoscale, vol. 7, no. 42, pp. 17957-17963, 2015.

[15] L. Bufalino, A. R. D. Neto, G. H. D. Tonoli et al., "How the chemical nature of Brazilian hardwoods affects nanofibrillation of cellulose fibers and film optical quality," Cellulose, vol. 22, no. 6, pp. 3657-3672, 2015.

[16] M. Guimarães, V. R. Botaro, K. M. Novack, F. G. Teixeira, and G. H. D. Tonoli, "High moisture strength of cassava starch/ polyvinyl alcohol-compatible blends for the packaging and agricultural sectors," Journal of Polymer Research, vol. 22, no. 10, p. 192, 2015.

[17] M. Guimarães, V. R. Botaro, K. M. Novack, F. G. Teixeira, and G. H. D. Tonoli, "Starch/PVA-based nanocomposites reinforced with bamboo nanofibrils," Industrial Crops and Products, vol. 70, pp. 72-83, 2015.

[18] O. Markovic, K. Heinrichová, and B. Lenkey, "Pectolytic enzymes from banana," Collection Czechoslovak Chemistry Community, vol. 40, no. 3, pp. 769-774, 1975.

[19] Association of Official Analytical Chemists (AOAC), Official Methods of Analysis of the Association of Official Analytical Chemists, AOAC, Washington, DC, USA, 18th edition, 2007.

[20] M. S. M. Rufino, R. E. Alves, S. M. Morais, C. G. Sampaio, J. Perez-Jimenez, and F. D. Saura-Calixto, Metodologia Científica: Determinação da Atividade Antioxidante Total Em Frutas Pela Captura do Radical Livre ABTS ${ }^{+}$, Embrapa Comunicado Técnico, Fortaleza, CE, Brazil, 2007.

[21] M. S. M. Rufino, R. E. Alves, S. M. Morais, C. G. Sampaio, J. Perez-Jimenez, and F. D. Saura-Calixto, Metodologia Científica: Determinação da Atividade Antioxidante Total Em Frutas Pela Captura do Radical Livre DPPH, Embrapa Comunicado Técnico, Fortaleza, CE, Brazil, 2007.

[22] M. S. M. Rufino, R. E. Alves, E. S. de Brito, J. M. Filho, and A. V. B. Moreira, Metodologia Científica: Determinação da AtividadeAntioxidante total Em Frutas no Sistema b-Caroteno/Ácido Linoléico, Embrapa Comunicado Técnico, Fortaleza, CE, Brazil, 2007.

[23] L. R. Strohecker and H. M. Henning, Análisis de Vitaminas: Métodos Comprobados, Madri Paz Montalvo, Madrid, Spain, 1967.

[24] A. L. Waterhouse, "Wine phenolics," Annals of the New York Academy of Sciences, vol. 957, no. 1, pp. 21-36, 2002.

[25] M. M. Giusti and R. E. Wrolstad, "Anthocyanins: characterization and measurement with UV-visible spectroscopy," in Current Protocols in Food Analytical Chemistry, E. R. Wrolstad, Ed., pp. 1-13, Wiley, New York, NY, USA, 2001. 
[26] H. Hyodo, H. Kurooa, and S. F. Yang, "Induction of phenylalanine ammonia-lyase and increase in phenolics in lettuce leaves in relation to the development of russet spotting caused by ethylene," Plant Physiology, vol. 62, no. 1, pp. 31-35, 1978.

[27] A. Casariego, B. W. S. Sousa, M. A. Cerqueira et al., "Chitosan/ clay films' properties as affected by biopolymer and clay micro/nanoparticles' concentrations," Food Hydrocolloids, vol. 23, no. 7, pp. 1895-1902, 2009.

[28] A. Jiménez, M. J. Fabra, P. Talens, and A. Chiralt, "Edible and biodegradable starch films: a review," Food and Bioprocess Technology, vol. 5, no. 6, pp. 2058-2076, 2012.

[29] S. J. Kim and Z. Ustunol, "Solubility and moisture sorption isotherms of whey-protein-based edible films as influenced by lipid and plasticizer incorporation," Journal of Agricultural and Food Chemistry, vol. 49, no. 9, pp. 4388-4391, 2001.

[30] D. W. S. Wong, F. A. Gastineau, S. S. Gregorski, S. J. Tillin, and A. E. Pavlajh, "Chitosan-lipid films: microstructure and surface energy," Journal of Agricultural and Food Chemistry, vol. 40, no. 4, pp. 540-544, 1992.

[31] N. E. Suyatma, A. Copinet, L. Tighzert, and V. Coma, "Mechanical and barrier properties of biodegradable films made from chitosan and poly(lactic acid) blends," Journal of Polymers and the Environment, vol. 12, no. 1, pp. 1-6, 2004.

[32] A. Kaushik, M. Singh, and G. Verma, "Green nanocomposites based on thermoplastic starch and steam exploded cellulose nanofibrils from wheat straw," Carbohydrate Polymers, vol. 82, no. 2, pp. 337-345, 2010.

[33] M. D. Sanchez-Garcia, E. Gimenez, and J. M. Lagaron, "Morphology and barrier properties of solvent cast composites of thermoplastic biopolymers and purified cellulose fibers," Carbohydrate Polymers, vol. 71, no. 2, pp. 235-244, 2008.

[34] A. J. Svagan, M. S. Hedenqvist, and L. Berglund, "Reduced water vapour sorption in cellulose nanocomposites with starch matrix," Composites Science and Technology, vol. 69, no. 3, pp. 500-506, 2009.

[35] J. M. Lagaron, R. Catalá, and R. Gavara, "Structural characteristics defining high barrier properties in polymeric materials," Materials Science and Technology, vol. 20, no. 1, pp. 1-7, 2004

[36] C. Ribeiro, A. A. Vicente, J. A. Teixeira, and C. Miranda, "Optimization of edible coating composition to retard strawberry fruit senescence," Postharvest Biology and Technology, vol. 44, no. 1, pp. 63-70, 2007.

[37] P. Hernández-Muñoz, E. Almenar, V. Del Valle, D. Velez, and R. Gavara, "Effect of chitosan coating combined with postharvest calcium treatment on strawberry (Fragaria $\mathrm{x}$ ananassa) quality during refrigerated storage," Food Chemistry, vol. 110, no. 2, pp. 428-435, 2008.

[38] G. A. Gonzalez-Aguilar, E. Valenzuela-Soto, J. LizardiMendoza et al., "Effect of chitosan coating in preventing deterioration and preserving the quality of fresh-cut papaya 'Maradol'," Journal of the Science of Food and Agriculture, vol. 89, no. 1, pp. 15-23, 2009.

[39] M. Vargas, A. Albors, A. Chiralt, and C. González-Martínez, "Quality of cold stored strawberries as affected by chitosan-oleic acid edible coatings," Postharvest Biology and Technology, vol. 41, no. 2, pp. 164-171, 2006.

[40] P. S. Tanada-Palmu and C. R. F. Grosso, "Effect of edible wheat gluten-based films and coatings on refrigerated strawberry quality," Postharvest Biology and Technolology, vol. 36, no. 2, pp. 199-208, 2005.

[41] S. H. A. Amal, M. M. El-Mogy, H. E. Aboul-Anean, and B. W. Alsanius, "Improving strawberry fruit storability by edible coating as a carrier of thymol or calcium chloride,"
Journal of Horticultural Science and Ornamental Plants, vol. 2, no. 3, pp. 88-97, 2010.

[42] S. Y. Wang and H. Gao, "Effect of chitosan-based edible coating on antioxidants, antioxidant enzyme system, and postharvest fruit quality of strawberries (Fragaria x aranassa Duch.)," LWT-Food Science and Technology, vol. 52, no. 2, pp. 71-79, 2013.

[43] A. El Ghaouth, J. Arul, J. Grenier, and A. Asselin, "Antifungal activity of chitosan on two postharvest pathogens of strawberry fruits," Postharvest Pathology and Mycotoxins, Phytopathology, vol. 82, no. 4, pp. 398-402, 1992.

[44] S. Eshghi, M. Hashemi, A. Mohammadi, F. Badii, Z. Mohammadhoseini, and K. Ahmadi, "Effect of nanochitosanbased coating with and without copper loaded on physicochemical and bioactive components of fresh strawberry fruit (Fragaria $\mathrm{x}$ ananassa Duchesne) during storage," Food and Bioprocess Technology, vol. 7, no. 8, pp. 2397-2409, 2014.

[45] H. Zhang, R. Li, and W. Liu, "Effects of chitin and its derivative chitosan on postharvest decay of fruits: a review," International Journal of Molecular Sciences, vol. 12, no. 2, pp. 917-934, 2011.

[46] B. S. Moore, C. Hertweck, J. N. Hopke et al., "Plant-like biosynthetic pathways in bacteria: from benzoic acid to chalcone," Journal of Natural Products, vol. 65, no. 12, pp. 1956-1962, 2002.

[47] Y. Katsuyama, T. Kita, N. Funa, and S. Horinouchi, "Curcuminoid biosynthesis by two type III polyketide synthases in the herb Curcuma longa," Journal of Biological Chemistry, vol. 284, no. 17, pp. 11160-11170, 2009.

[48] M. J. MacDonald and G. B. D'Cunha, "A modern view of phenylalanine ammonia lyase," Biochemistry and Cell Biology, vol. 85, no. 3, pp. 273-282, 2007.

[49] Y. W. A. El-Shiekh, N. H. El-Din, M. A. A. Shaymaa, and K. A. Z. El-Din, "Antifungal activity of some naturally occurring compounds against economically important phytopathogic fungi," Natural Sciences, vol. 10, pp. 114-123, 2012.

[50] A. M. Durango, N. F. F. Soares, and N. J. Andrade, "Microbiological evaluation of an edible antimicrobial coating on minimally processed carrots," Food Control, vol. 17, no. 5, pp. 336-341, 2006.

[51] G. K. Agrawal, R. Rakwal, S. Tamogami, M. Yonekura, A. Kubo, and H. Saji, "Chitosan activates defense/stress response(s) in the leaves of Oryza sativa seedlings," Plant Physiology and Biochemistry, vol. 40, no. 12, pp. 1061-1069, 2002.

[52] F. Brunel, N. E. El Gueddari, and B. M. Moerschbacher, "Complexation of copper (II) with chitosan nanogels: toward control of microbial growth," Carbohydrate Polymers, vol. 92, no. 2, pp. 1348-1356, 2013. 


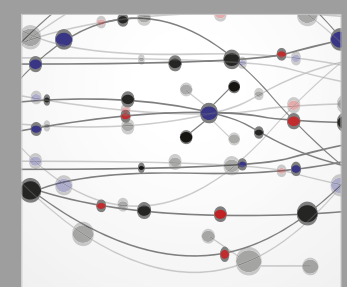

The Scientific World Journal
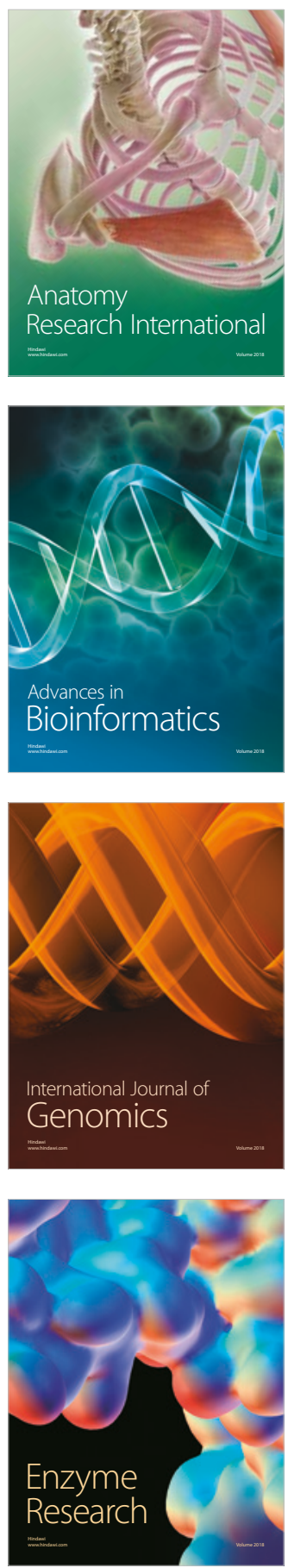
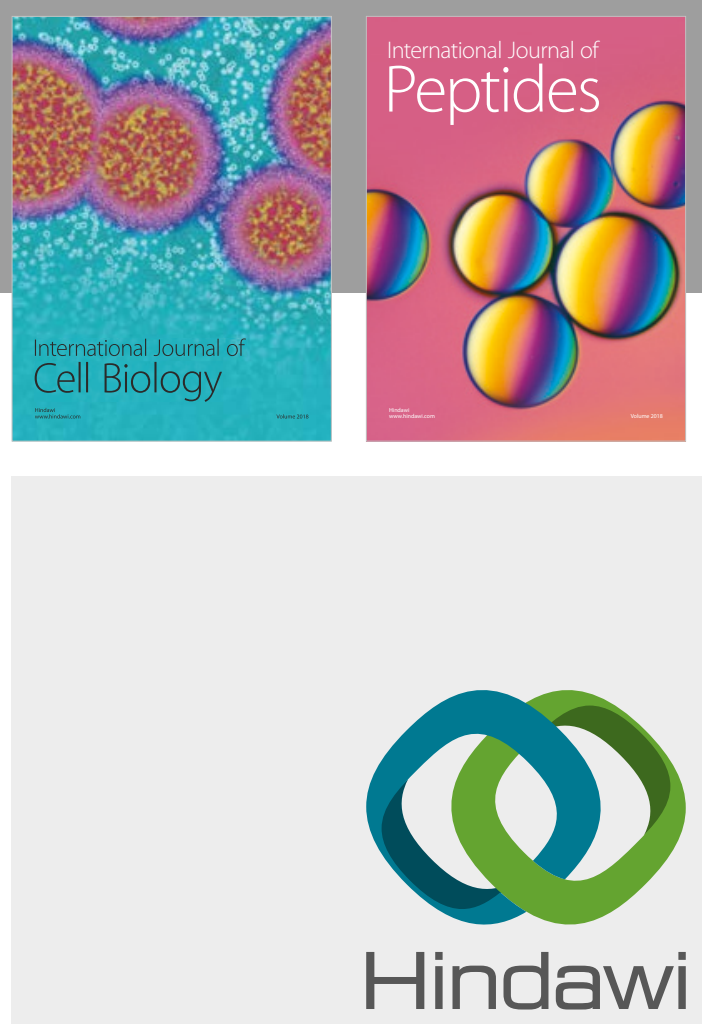

Submit your manuscripts at

www.hindawi.com
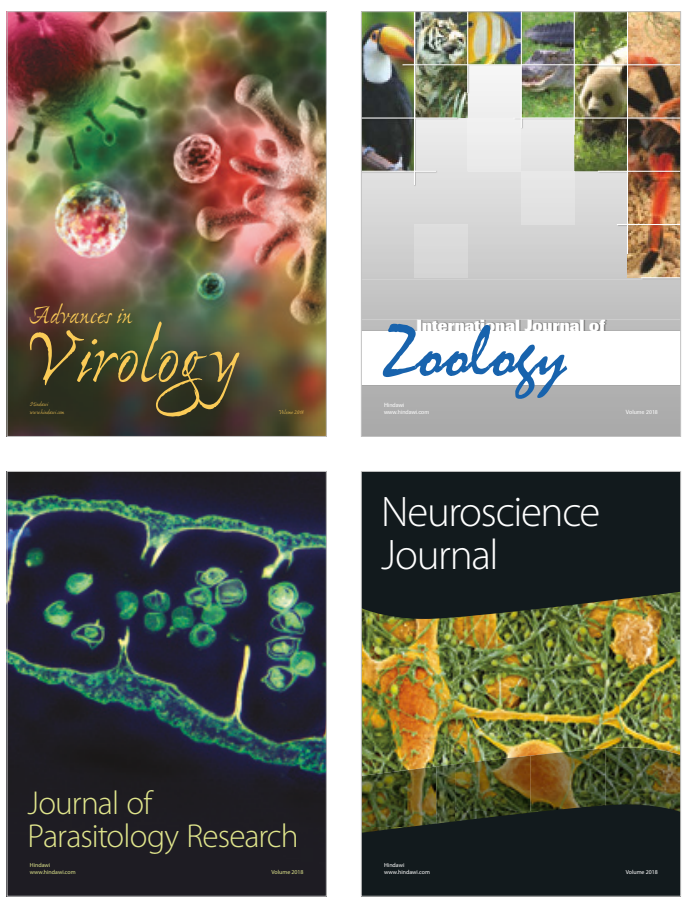
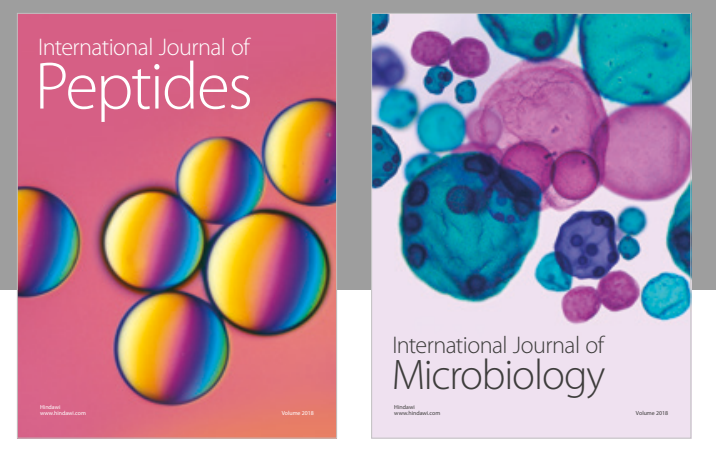

nternational Journal of Microbiology
Journal of
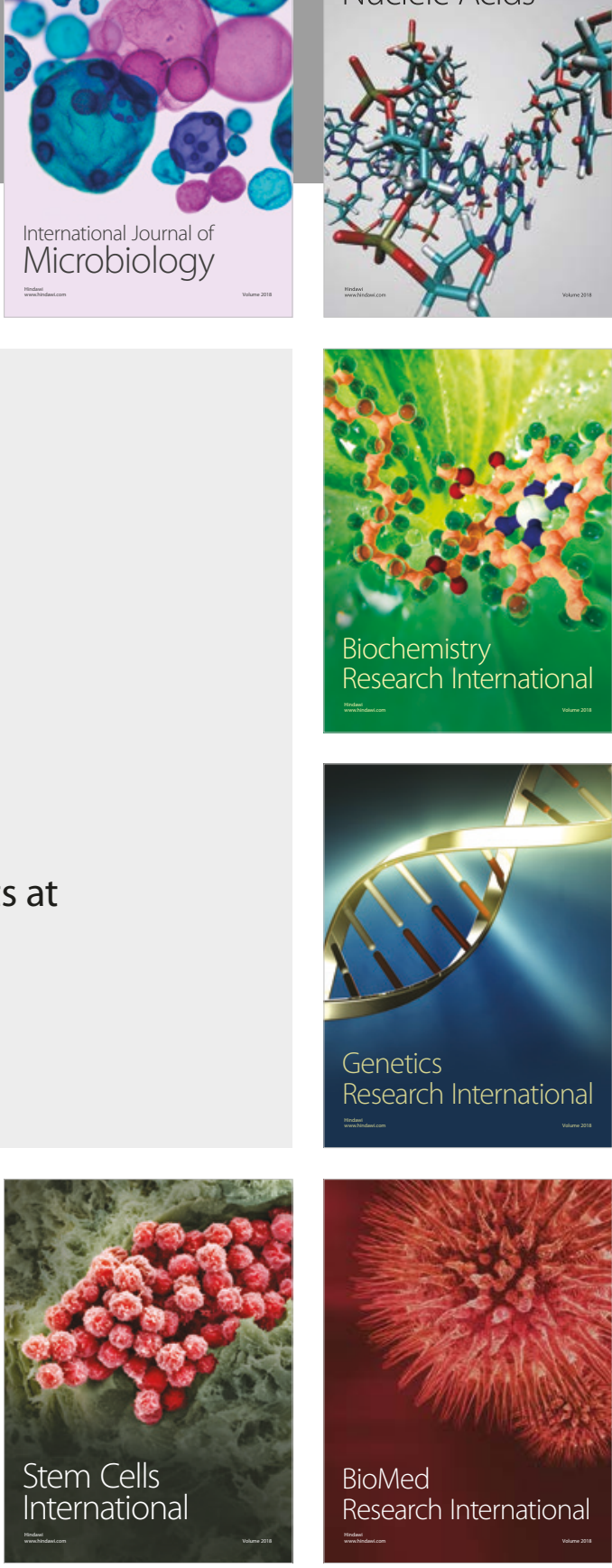
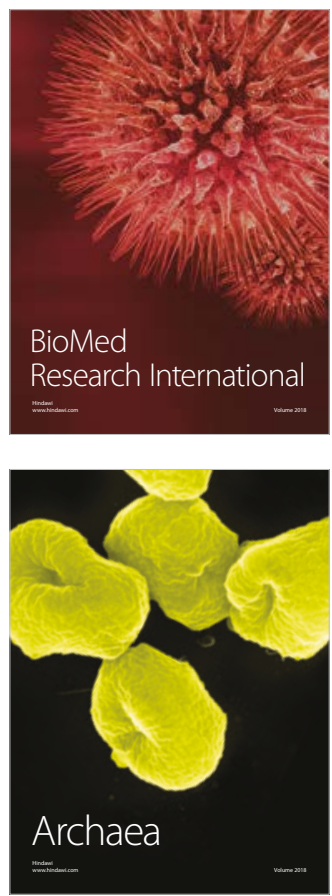